\title{
Selective inhibition of COX-2 in humans is associated with less gastrointestinal injury: a comparison of nimesulide and naproxen
}

\author{
A A Shah, B Thjodleifsson, F E Murray, E Kay, M Barry, G Sigthorsson, H Gudjonsson, \\ E Oddsson, A B Price, D J Fitzgerald, I Bjarnason
}

\begin{abstract}
Background-Selective inhibitors of cyclooxygenase (COX)-2 may provoke less gastric damage and platelet inhibition than conventional non-steroidal antiinflammatory drugs.

Aims-We compared the biochemical and gastrointestinal effects of nimesulide, a potent and selective COX-2 inhibitor, with naproxen which exhibits no selectivity. Subjects-Thirty six healthy volunteers were randomised to nimesulide $100 \mathrm{mg}$ or naproxen $500 \mathrm{mg}$ twice daily for two weeks in a double blind, crossover study with a washout between treatments.

Methods-Gastrointestinal side effects were assessed by endoscopy, and by estimation of small intestinal absorptionpermeability and inflammation. Comparisons were made between variables at the end of each treatment phase. Results-Nimesulide caused significantly less gastric injury using the modified Lanza score $(p<0.001)$ as well as reduced duodenum injury $(p=0.039)$. Nimesulide had lower visual analogue scores (VAS) for haemorrhage and erosive lesions in the stomach $(p<0.001)$ and for mucosal injection in the duodenum $(p=0.039)$. Naproxen increased excretion of calprotectin, a marker of intestinal inflammation (5.5 (1.2) to $12.1(2.1) \mathrm{mg} / \mathrm{l})$ while nimesulide had no effect (treatment difference p =0.03). Naproxen abolished platelet aggregation to arachidonic acid and suppressed serum thromboxane $\mathrm{B}_{2}\left(\mathrm{TXB}_{2}\right)$ by $\mathbf{9 8 \%}$, indices of COX-1 activity. In contrast, nimesulide had no significant effect on platelet aggregation, although it reduced serum $\mathrm{TXB}_{2}$ by $29 \%$. Production of prostaglandin $\mathrm{E}_{2}$ and prostacyclin by gastric biopsies, also COX-1 dependent, was inhibited by naproxen, but not by nimesulide. COX-2 activity, determined as endotoxin induced prostaglandin $E_{2}$ formation in plasma, was markedly suppressed by both treatments.

Interpretation-Nimesulide has preferential selectivity for COX-2 over COX-1 in vivo at full therapeutic doses and induces less gastrointestinal damage than that seen with naproxen in the short term. (Gut 2001;48:339-346)
\end{abstract}

Keywords: cyclooxygenase; prostaglandins; platelet aggregation; non-steroidal anti-inflammatory drug enteropathy
Non-steroidal anti-inflammatory drugs (NSAIDs) are a major cause of iatrogenic gastrointestinal injury. ${ }^{1-6}$ Gastrointestinal toxicity is particularly evident in the stomach ${ }^{2}$ and duodenum,,$^{57}$ although injury occurs throughout the bowel. ${ }^{5}$ Cross sectional endoscopic studies in patients receiving NSAIDs show an ulcer prevalence of $10-25 \%$ with significant attendant mortality and morbidity. ${ }^{89}$ NSAIDs may also injure the small intestine, leading to a spectrum of damage from a change in permeability through to inflammation and ulceration, which may lead to anaemia ${ }^{10}$ and occasionally stricture formation. ${ }^{11}$

NSAIDs are inhibitors of cyclooxygenase (COX) and prostaglandin (PG) formation. Two isoforms of the enzyme have been identified, COX $-1^{12}$ which is present in most cells, and COX $-2^{13}$ which is largely absent in normal tissue but is inducible by cytokines, growth factors, and hormones, ${ }^{14-16}$ and is expressed at the site of inflammation. ${ }^{17} \mathrm{COX}-1$ is largely responsible for PG formation in the stomach and duodenum, ${ }^{18}{ }^{19}$ although COX-2 expression has been reported. COX-1 is the only form of the enzyme found in platelets. Inhibition of COX-1 in the stomach, where the major product is $\mathrm{PGE}_{2},{ }^{19}$ may be responsible in part for the injury seen with NSAIDs. ${ }^{6}$ Moreover, in experimental models, selective inhibition of COX-2 is associated with minimal or no gastrointestinal damage. ${ }^{20}$ Concomitant inhibition of COX-1 in platelets may also contribute to the haemorrhagic complications of gastrointestinal damage as this inhibits platelet thromboxane (TX) formation and aggregation, and prolongs bleeding time..$^{22}$

The majority of currently available NSAIDs inhibit both isoforms of the enzyme to a similar extent. ${ }^{23}$ An important development has been the identification of several compounds with selectivity towards COX-2. ${ }^{24}{ }^{25}$ These compounds offer the potential for suppressing COX-2 at sites of inflammation while preserving COX-1 in the stomach and platelets. Consequently, COX-2 inhibitors may induce less gastric injury and haemostatic impairment. Here, we compare the gastrointestinal tolerability and in vivo biochemical selectivity of nimesulide, a relatively selective inhibitor of

Abbreviations used in this paper: NSAID, non-steroidal anti-inflammatory drug; COX, cyclooxygenase; PG, prostaglandin; TX, thromboxane; VAS, visual analogue score; LPS, lipopolysaccharide; $\mathrm{PGI}_{2}$, prostacyclin; ADP, adenosine diphosphate;

TRAP, thrombin receptor activator peptide. 
$\mathrm{COX}-2^{26}{ }^{27}$ in vitro, with the non-selective COX inhibitor naproxen.

\section{Subjects and methods}

SUBJECTS

Thirty six healthy volunteers, aged 40-67 years, were recruited from two centres, Beaumont Hospital Dublin, Ireland $(n=13)$ and University Hospital Reykjavik, Iceland $(n=23)$. Specific exclusion criteria were a past history of intolerance to NSAIDs, modified Lanza score of $>1$ at baseline endoscopy, past history of peptic ulcer disease, or any other clinically significant medical disorder. The ethics committees of the participating hospitals approved the study protocol and written informed consent was obtained from all subjects.

\section{STUDY DESIGN}

At the start of period 1, subjects were randomly assigned to receive naproxen $500 \mathrm{mg}$ twice daily and nimesulide placebo or nimesulide $100 \mathrm{mg}$ twice daily and naproxen placebo for two weeks. The first period was followed by a two week washout and then subjects were assigned to the alternate therapies. The randomisation list was prepared using the software Rancode, v 3.1 (Gauting, Germany).

GASTRODUODENAL EVALUATION

Endoscopic evaluation of subjects was performed at the start and end of each period. Gastric and duodenal damage was assessed separately using a modified Lanza score ${ }^{28}$ (tables 1,2 ) and visual analogue score (VAS). ${ }^{29}$ For the Lanza score, a score of 0 indicated no lesion, a single erosion or submucosal haemorrhage was given a score of $1,2-10$ erosions or submucosal haemorrhages a score of $2,>10$ erosions or submucosal haemorrhages a score of 3, and an ulcer a score of 4. Lanza score 4 ("ulcer") required an excavated mucosal break of $5 \mathrm{~mm}$ or more. For VAS scoring, the severity of two parameters, haemorrhagic and erosive lesions in the stomach and duodenum, was assessed along a linear $150 \mathrm{~mm}$ scale. Haemorrhagic lesions ranged from the presence of a few single petechiae to profuse bleeding in the stomach or duodenum, and erosive lesions from one erosion to frank ulceration.

The washout period was extended for up to four weeks if gastroduodenal damage had not returned to normal by the beginning of period 2. At each endoscopy, the presence of Helicobacter pylori was determined by the rapid urease activity assay (CLO test) and in four biopsy specimens, two each from the antrum and corpus by histology. All samples were stained with haematoxylin and eosin, a cresyl fast violet stain for $H$ pylori, and Gomori's aldehyde fuchsin to identify intestinal metaplasia.

Gastritis was assessed according to a modified Sydney system ${ }^{30}$ which consists of a simple scoring system: absent $=0$, minimal $=1$, mild $=2$, moderate $=3$, and severe $=4$. The parameters scored were those associated with $H$ pylori, chronic inflammation, acute inflammation, atrophy, and metaplasia. The highest possible total score was 20 for the antrum or corpus, but any score above 0 was regarded as abnormal.
Reactive or chemical gastritis is associated with the use of NSAIDs. Parameters indicative of these changes were also documented and scored as follows: foveolar hyperplasia, arborisation of the muscularis into the mucosa, oedema, hyperaemia, paucity of inflammation, and atrophy. The maximum score was 24 for the antrum and corpus. A score of 6 or less was considered insignificant.

INTESTINAL ABSORPTION-PERMEABILITY

The 23 subjects from Iceland underwent a combined absorption-permeability test two days prior to and on day 10 of both the nimesulide and naproxen treatment periods, one hour following drug ingestion. ${ }^{31}$ All subjects abstained from alcohol and any medicines known to influence permeability and absorption. After an overnight fast, a test solution $(100 \mathrm{ml}$ of $3-o$-methyl-D-glucose $(0.2 \mathrm{~g})$, D-xylose $(0.5 \mathrm{~g})$, L-rhamnose $(1.0 \mathrm{~g})$, and lactulose $(5.0 \mathrm{~g})$ ) was administered orally and urine collected over five hours into $1 \mathrm{ml}$ of $10 \%$ mercurithiosalicylate as preservative. Urinary sugars were determined by thin layer chromatography and scanning densitometry. ${ }^{32}$ The assay is sensitive, has $95 \%$ recovery, and a coefficient of variation of $2-8 \% .^{33} 34$

This test assesses several small intestinal transcellular functions and paracellular integrity. 3-o-Methyl-D-glucose is absorbed by active carrier mediated process, $\mathrm{D}$-xylose by a passive carrier mediated process, and L-rhamnose by a non-mediated transcellular transport system. Lactulose on the other hand permeates selectively across the paracellular junctions of the adjacent enterocytes. ${ }^{31}{ }^{35}$ The differential urinary excretion of lactulose /Lrhamnose provides a specific index of intestinal permeability (intestinal barrier function). This permeability index is quite specific for mucosal function and is not significantly altered by pre(gastric and intestinal dilution, gastric emptying, bacterial degeneration, etc) or post(volume of distribution, renal function, etc) mucosal factors that can effect urinary excretion of these markers following ingestion. ${ }^{31}{ }^{35}$

INTESTINAL INFLAMMATION

Twenty three subjects in Iceland provided a stool specimen for measurement of calprotectin concentration (a non-degraded, neutrophil specific marker) on the same day as the intestinal absorption-permeability test. Samples of stool $(20 \mathrm{~g})$ were frozen and stored at $-20^{\circ} \mathrm{C}$. After thawing, $5 \mathrm{~g}$ aliquots were suspended in $10 \mathrm{ml}$ of faecal extraction buffer (Tris buffered isotonic $(150 \mathrm{mM})$ saline, $10 \mathrm{mM} \mathrm{CaCl}$, and $0.25 \mathrm{mM}$ thiomersal as antimicrobial agent, $\mathrm{pH}$ 8.4) and homogenised for one minute with an Ultra Turrax (Ika Werke, Germany) mechanical homogeniser. The homogenates were centrifuged at $10000 \mathrm{~g}$ at $+4^{\circ} \mathrm{C}$. The top halves of the supernatants were pipetted off, frozen, and stored at $-20^{\circ} \mathrm{C}$ until quantitation by ELISA. ${ }^{36} 37$

The normal range of faecal calprotectin excretion and concentration was established in 53 healthy volunteers ( 30 males, median age 36 years (range 18-60)) and in 36 patients with 
irritable bowel syndrome (10 men, median age 34 years (range 28-54)). Normal median calprotectin concentration was $3 \mathrm{mg} / \mathrm{l}$ with an upper limit (98\% confidence limit) of $11 \mathrm{mg} / \mathrm{l}$.

EFFECT OF DRUGS ON COX-1 AND COX-2 ACTIVITY The effect of nimesulide and naproxen on COX-1 and COX-2 was assessed by several methods. Platelet aggregation and gastric mucosal PG generation were assessed in 13 Irish volunteers as a parameter of a COX-1 dependent process both before and during treatment with nimesulide and naproxen. In all 36 subjects, serum $\mathrm{TXB}_{2}$ (reflecting COX-1 activity) ${ }^{25}$ and lipopolysaccharide (LPS) induced $\mathrm{PGE}_{2}$ synthesis (reflecting COX-2 activity) ${ }^{38}$ in whole blood was measured both before and during treatment with nimesulide and naproxen.

GASTRIC MUCOSAL PROSTANOID SYNTHESIS

Prior to and on day 15 of treatment with nimesulide and naproxen in the 13 volunteers studied in Ireland, antral mucosal biopsies were obtained for determination of PGs $\left(\mathrm{PGE}_{2}\right.$ and 6-keto $\mathrm{PGF}_{10}$, a metabolite of prostacyclin $\left(\mathrm{PGI}_{2}\right)$ ). Antral biopsies were incubated at $37^{\circ} \mathrm{C}$ for 45 minutes in $250 \mu 1$ of phosphate buffered saline and the supernatant stored at $-20^{\circ} \mathrm{C}$ for subsequent analysis. $\mathrm{PGE}_{2}$ was measured by enzyme immunoassay (EIA) (Assay Design, Ann Arbour, Michigan, USA). The lower limit of detection of this assay is 36.2 $\mathrm{pg} / \mathrm{ml}$ and cross reactivity is $\mathrm{PGE}_{1} 70 \%$ and $\mathrm{PGE}_{3} \quad 16.3 \%$. Cross reactivity with other eicosanoids is negligible. $\mathrm{PGI}_{2}$ was determined as its hydrolysis product, 6- keto-PGF PG $_{1 \alpha}$ (Assay Design). The sensitivity of this method is 1.4 $\mathrm{pg} / \mathrm{ml}$, and the cross reactivity with 2,3 dinor 6 -keto-PGF ${ }_{1 \alpha}$ is $4 \%$ and negligible with other compounds. After analysis, total protein in each biopsy tissue was assessed (Bio-Rad DC, Hertfordshire UK) and the PG generated expressed as $\mathrm{ng} / \mathrm{mg}$ protein.

SERUM THROMBOXANE SYNTHESIS

For serum $\mathrm{TXB}_{2}, 5 \mathrm{ml}$ blood samples were taken prior to treatment and on days 3, 10, and day 15, one hour after dosing, placed in non-siliconised glass tubes prewarmed to $37^{\circ} \mathrm{C}$ and incubated at this temperature for one hour. Serum was separated and stored at $-20^{\circ} \mathrm{C}$ until analysis by EIA (Assay Design). ${ }^{25}$ The sensitivity of this method is $8 \mathrm{pg} / \mathrm{ml}$, while cross reactivity is $7.1 \%$ with 2,3 -dinor- $\mathrm{TXB}_{2}$ and negligible with other compounds.

PLATELET FUNCTION

Platelet aggregation was evaluated in 13 subjects. Blood was obtained in $3.2 \%$ sodium citrate $(9: 1 \mathrm{v} / \mathrm{v})$ predose, and on days 3 and 10 of treatment, at a time (1-2 hours following the morning dose) corresponding to peak plasma drug levels. Samples were centrifuged at $190 \mathrm{~g}$ for 15 minutes to obtain platelet rich plasma and at $900 \mathrm{~g}$ for a further 10 minutes to obtain platelet poor plasma. Platelet aggregation was assessed by light transmission (BioData PAP 4, Malvern, Pennsylvania, USA) in response to arachidonic acid $0.33 \mathrm{mM}$ (entirely $\mathrm{TXA}_{2}$ dependent), adenosine diphosphate (ADP) 10

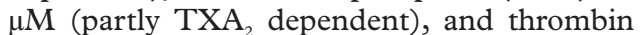
receptor activator peptide (TRAP) $20 \mu \mathrm{M}$ (TXA ${ }_{2}$ independent). The response was determined as maximum platelet aggregation at four minutes.

COX-2 INHIBITION

COX-2 activity was assessed by estimation of LPS induced $\mathrm{PGE}_{2}$ formation in whole blood. ${ }^{38}$ For analysis of $\mathrm{PGE}_{2}, 5 \mathrm{ml}$ of whole blood were added to a tube containing a final concentration of aspirin $200 \mu \mathrm{M}$ (to inactivate any COX activity) and LPS $1 \mu \mathrm{g} / \mathrm{ml}$ (to induce COX-2 expression) in water and incubated at $37^{\circ} \mathrm{C}$ for 24 hours. Samples were centrifuged for 10 minutes at $900 \mathrm{~g}$ and plasma stored at $-20^{\circ} \mathrm{C}$ until analysed by ELISA (Assay Design), as described above.

PLASMA DRUG LEVELS

Plasma naproxen and nimesulide levels were determined one and two hours following administration of the last dose, corresponding to peak plasma drug levels. Plasma naproxen levels were determined by fluorometric detection following liquid-liquid extraction on the Merck-Hibar Lichrosorb RP18 using a mobile phase of $0.05 \mathrm{M}$ phosphate $\mathrm{pH} 3$ buffer, methanol, and acetonitrile acid (50/25/25 $\mathrm{v} / \mathrm{v} / \mathrm{v})$. The limit of sensitivity was $0.5 \mu \mathrm{g} / \mathrm{ml}$. Plasma nimesulide was determined by high performance liquid chromatography with UV detection. The limit of detection was 0.01 $\mu \mathrm{g} / \mathrm{ml}$.

\section{STATISTICAL ANALYSIS}

The sample size was determined for the primary outcome measure, the modified Lanza score. Based on the assumption that the Lanza score would increase above 1 in $65 \%$ of naproxen treated subjects and in $25 \%$ of those receiving nimesulide, a bimodal distribution for two paired group analysis was used to compute sample sizes. The rate of subjects giving different results in different periods (rate of switchers) was estimated by computing the probability of remaining normal (Lanza $\leqslant 1$ ) on nimesulide and abnormal on naproxen and vice versa and was $57 \%$. Using a two sided test difference, we estimated that at least 29 subjects would be required ( $\alpha=0.05, \beta=0.1$ ). Statistical analysis was on a per protocol basis as the design was crossover. A crossover analysis was performed taking in the baseline values and the final values for each period.

For the Lanza score data, two analyses were performed. A categorical analysis was performed where individuals were defined as normal (Lanza score $\leqslant 1$ ) or abnormal (Lanza score $>1)$. The number of subjects belonging to the four categories of possible (binomial) results (normal on naproxen but abnormal on nimesulide; normal on nimesulide but abnormal on naproxen; normal on both; abnormal on both) was assessed by the McNemar $\chi^{2}$ test. In addition, the raw Lanza scores, VAS, and biochemical analyses were analysed using a $\mathrm{Koch}^{39}$ test. Only the results from the analysis of treatment effects (which uses the Wilcoxon 
matched pairs test) are presented here. As non-parametric tests have been used for statistical analysis, medians are presented throughout, although mean and standard errors are also presented for biochemical results. Friedman analysis for multiple comparisons within treatments has been used to identify changes from baseline for the naproxen and nimesulide groups separately.

Table 1 Gastric damage scores (modified Lanza score): comparison of treatment effects of nimesulide and naproxen, and comparison of responders (Lanza score 0,1) and non-responders (Lanza score $>1$ )

\begin{tabular}{|c|c|c|c|c|c|c|}
\hline \multirow[b]{2}{*}{ Lanza score ${ }^{\star}$} & \multicolumn{5}{|l|}{ Nimesulide } & \multirow[b]{2}{*}{$\begin{array}{l}\text { Total } \\
\text { naproxen }\end{array}$} \\
\hline & 0 & 1 & 2 & 3 & 4 & \\
\hline \multicolumn{7}{|l|}{ Naproxen } \\
\hline 0 & 3 & 0 & 1 & 0 & 0 & $4(11 \%)$ \\
\hline 1 & 2 & 0 & 0 & 0 & 0 & $2(6 \%)$ \\
\hline 2 & 5 & 1 & 2 & 1 & 0 & $9(26 \%)$ \\
\hline 3 & 8 & 3 & 5 & 0 & 0 & $16(46 \%)$ \\
\hline 4 & 2 & 1 & 1 & 0 & 0 & $4(11 \%)$ \\
\hline Total nimesulide (\%) & $20(57 \%)$ & $5(14 \%)$ & $9(26 \%)$ & $1(3 \%)$ & $0(0 \%)$ & 35 \\
\hline
\end{tabular}

Analysis of responders $†$

\begin{tabular}{lll} 
& \multicolumn{2}{l}{ Nimesulide } \\
\cline { 2 - 3 } & Responder $(0,1)$ & Non-responder $(2,3,4)$ \\
\hline Naproxen & 5 & 1 \\
$\quad$ Responder & 20 & 9 \\
\hline
\end{tabular}

McNemar test: $\mathrm{p}<0.001$ (two sided)

${ }^{\star}$ Modified Lanza score: 0 , normal; 1, erosion or submucosal haemorrhage; 2, 2-10 erosions or submucosal haemorrhages; $3,>10$ erosions or submucosal haemorrhage; 4 , ulcer.

tResponder is a Lanza score of 0 or 1 ; a non-responder is a Lanza score of $>1$.

Table 2 Duodenal damage scores (modified Lanza score): comparison of treatment effects of nimesulide and naproxen, and comparison of responders (Lanza score 0,1) and non-responders (Lanza score $>1$ )

\begin{tabular}{|c|c|c|c|c|c|c|}
\hline \multirow[b]{2}{*}{ Lanza score* } & \multicolumn{5}{|l|}{ Nimesulide } & \multirow[b]{2}{*}{$\begin{array}{l}\text { Total } \\
\text { naproxen }\end{array}$} \\
\hline & 0 & 1 & 2 & 3 & 4 & \\
\hline \multicolumn{7}{|l|}{ Naproxen } \\
\hline 0 & 15 & 3 & 1 & 0 & 1 & $20(57 \%)$ \\
\hline 1 & 3 & 0 & 0 & 0 & 0 & $4(11 \%)$ \\
\hline 2 & 6 & 1 & 1 & 0 & 0 & $7(20 \%)$ \\
\hline 3 & 3 & 0 & 0 & 0 & 0 & $3(9 \%)$ \\
\hline 4 & 1 & 0 & 0 & 0 & 0 & $1(3 \%)$ \\
\hline Total nimesulide (\%) & $28(80 \%)$ & $4(11 \%)$ & $2(6 \%)$ & $0(0 \%)$ & $1(3 \%)$ & 35 \\
\hline
\end{tabular}

Analysis of responderst

Nimesulide

\begin{tabular}{lll}
\cline { 2 - 3 } & Responder $(0,1)$ & Non-responder $(2,3,4)$ \\
\hline Naproxen & & \\
Responder & 22 & 2 \\
Non-responder & 10 & 1 \\
\hline
\end{tabular}

McNemar test: $\mathrm{p}<0.001$ (two sided)

${ }^{\star}$ Modified Lanza score: 0, normal; 1, erosion or submucosal haemorrhage; 2, 2-10 erosions or submucosal haemorrhages; $3,>10$ erosions or submucosal haemorrhage; 4 , ulcer.

†Responder is a Lanza score of 0 or 1 ; a non-responder is a Lanza score of $>1$.

Table 3 Gastric and duodenal damage score (visual analogue score): comparison of treatment effects of nimesulide and naproxen (mean (SEM) and [median])

\begin{tabular}{lclll}
\hline Type VAS & Nimesulide & Naproxen & Nap-Nim & p Value* \\
\hline Stomach & & & & \\
Haemorrhage lesions & $14.0(3.8)[0]$ & $40.6(6.0)[50]$ & $26.5(6.5)[12]$ & $<0.001$ \\
Erosive lesions & $9.2(2.9)[0]$ & $61.7(7.8)[52]$ & $52.5(7.3)[51]$ & $<0.001$ \\
Mucosal injection & $24.8(4.2)[25]$ & $47.9(3.8)[48]$ & $23.1(5.2)[22]$ & $<0.001$ \\
Duodenum & & & & \\
Haemorrhage lesions & $5.3(3.0)[0]$ & $11.5(4.3)[0]$ & $6.2(4.5)[0]$ & 0.165 \\
Erosive lesions & $5.5(4.3)[0]$ & $15.3(5.7)[0]$ & $9.9(7.5)[0]$ & 0.181 \\
Mucosal injection & $9.2(2.8)[0]$ & $22.5(3.9)[21]$ & $13.3(4.2)[1]$ & 0.038
\end{tabular}

${ }^{\star}$ Koch test for difference between nimesulide and naproxen.

\section{Results}

Twenty four males and 12 females were recruited from the two centres. Demographic details and outcome measures were similar for the two centres and hence data from the two sites are presented jointly. The average age of subjects was 48 years (range 39-67). One male subject developed severe gastric damage at the end of the first treatment period where he had received naproxen, and as there was persistent ulceration four weeks later he was withdrawn from the study. As statistical analyses for crossover designs require patients to attend for more than one treatment period, this patient was omitted from these statistical analyses. Unless otherwise stated, data from 35 patients have been used for analyses.

\section{ENDOSCOPIC EVALUATION}

The results of the grading of gastrointestinal damage on the modified Lanza scale are shown in tables 1 and 2. One subject in the nimesulide group developed multiple $(>10)$ gastric erosions and a separate subject developed a duodenal ulcer. By comparison, in the naproxen group, 16 developed multiple gastric erosions, four developed a gastric ulcer, three developed multiple duodenal erosions, and one a duodenal ulcer. Considering the main variable (rate of responders), the McNemar $\chi^{2}$ test (two sided) analyses of patients categorised as normal (Lanza score $\leqslant 1$ ) or abnormal (Lanza score $>1$ ) showed that nimesulide was better tolerated than naproxen $(p<0.001$ in the stomach and $\mathrm{p}=0.039$ in the duodenum). Examining the raw scores, the median treatment difference was -2 due to worse scores with naproxen. For the VAS (table 3, fig 1) of haemorrhagic lesions in the stomach, scores were greater (worse) with naproxen (median 50) compared with nimesulide (median 0). The difference between treatments was significant ( $\mathrm{p}<0.001$, Koch test, two sided). A similar result was evident for erosive lesions in the stomach $(p<0.001)$, mucosal injection in the stomach $(\mathrm{p}<0.001)$, and mucosal injection in the duodenum $(p=0.038)$. No treatment differences were evident when comparing haemorrhage or erosive lesions in the duodenum. Comparison of Lanza scores for duodenal mucosal damage showed no difference (both median scores were zero, as was the median treatment difference).

Histological examination of the gastric biopsies showed that 19 of the 36 analysed subjects were positive for $H$ pylori prior to the first treatment. This was found not to affect the baseline Lanza scores as the mean stomach score (averaged over the results for both treatments) was similar regardless of $H$ pylori status (positive patients, mean 0.05 (0.05), median 0; negative patients, mean $0.29(0.11)$, median 0$)$. Moreover, the presence of $H$ pylori did not influence the response to treatment.

\section{INTESTINAL ABSORPTION-PERMEABILITY AND} INFLAMMATION

Table 4 shows the results of the combined absorption-permeability tests. Neither treatment altered the absorption parameters (uri- 


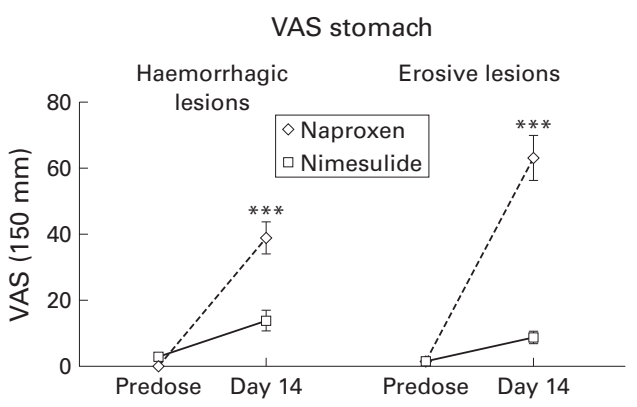

VAS duodenum

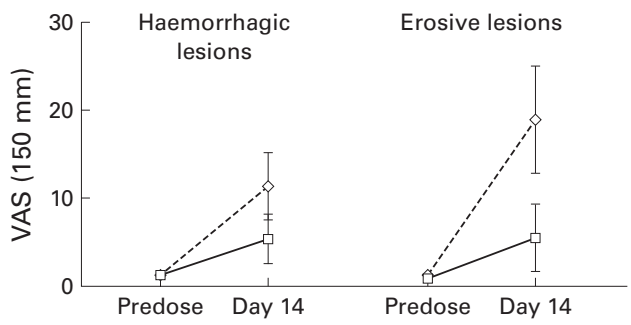

Figure 1 Comparison of the effects of nimesulide and naproxen on visual analogue scores (VAS) at endoscopy of the upper gastrointestinal tract before and during treatment with nimesulide $100 \mathrm{mg}$ twice daily or naproxen $500 \mathrm{mg}$ twice daily. Data are shown as mean (SEM). $\star \star \star p<0.001$ between treatments.

nary excretion of 3-o-methyl-D-glucose, D-xylose, L-rhamnose). Naproxen increased intestinal permeability as reflected by an increase in the differential urinary excretion of lactulose/L-rhamnose, whereas nimesulide had no such effect; however, the treatment difference was not statistically significant on day 10 .

\section{INTESTINAL INFLAMMATION}

Calprotectin concentration was determined in the faeces of 23 subjects as a marker of intestinal inflammation. The change from baseline to day 10 showed a significant treatment effect $(\mathrm{p}=0.03)$. Nimesulide had no effect over the 10 days (6.1 (2.3) $\mathrm{mg} / \mathrm{l}$ (range 0.5-55.0) $v 6.9$ (1.3) $\mathrm{mg} / \mathrm{l}$ (range 0.5-25)) whereas naproxen increased calprotectin excretion $(5.5(1.2) \mathrm{mg} / \mathrm{l}$ (range 0-25) v 12.1 (2.1) mg/1 (range 0-43)).

\section{EICOSANOIDS GENERATION}

$\mathrm{PGE}_{2}$ and $\mathrm{PGI}_{2}$ (measured as 6-keto $\mathrm{PGF}_{10}$ ) generation by gastric biopsy was similar to that reported previously. ${ }^{40}$ Generation of both products was markedly reduced by naproxen but not by nimesulide and there was a significant difference between treatments $\left(\mathrm{p}<0.01\right.$ ) (fig 2). Serum $\mathrm{TXB}_{2}$ was markedly inhibited by naproxen, falling by $98 \%$ throughout the treatment period. For nimesulide, there was a small decrease from baseline to day 3
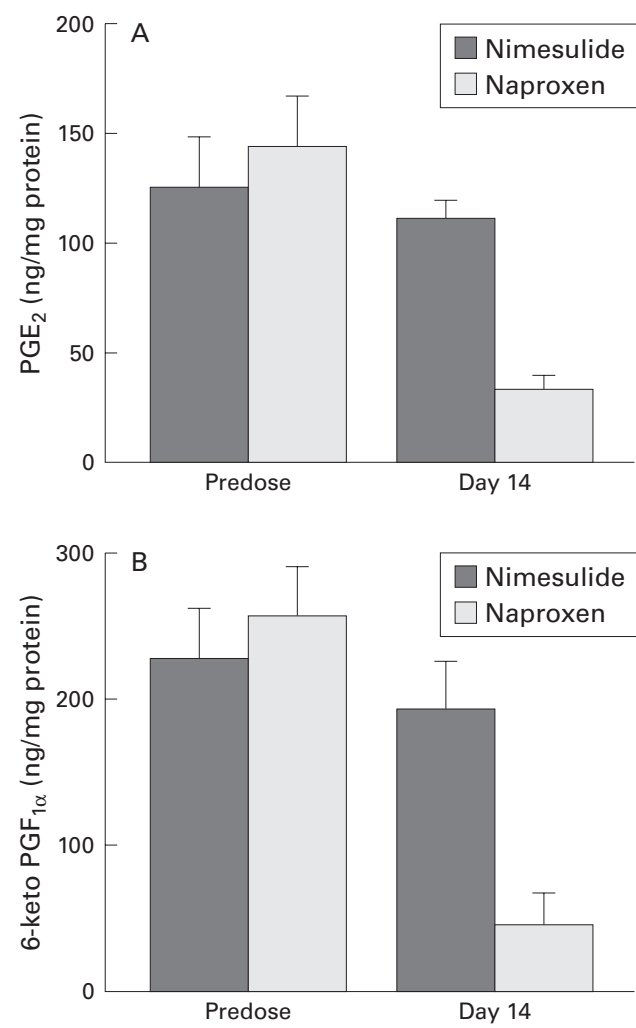

Figure 2 Comparison of the effects of nimesulide and naproxen on generation of prostaglandin $(P G) E_{2}(A)$ and 6-keto-PGF $F_{1 a}(B)$ by gastric biopsies incubated at $37^{\circ} \mathrm{C}$ for 45 minutes before and during treatment with nimesulide $100 \mathrm{mg}$ twice daily or naproxen $500 \mathrm{mg}$ twice daily. Data are shown as mean (SEM). $p<0.01$ between treatments.

(273 (13) $v 180(15) \mathrm{ng} / \mathrm{ml}$ ) which resulted in an average decrease of $29 \%$ throughout the treatment period (treatment effect was $\mathrm{p}<0.001$ for the change from baseline to day 10) (fig 3A). LPS induced $\mathrm{PGE}_{2}$ in plasma, which reflects COX-2 activity, was evaluated in 33 subjects. Plasma $\mathrm{PGE}_{2}$ decreased by $74 \%$ on naproxen, less than the $93 \%$ reduction seen with nimesulide $(p=0.053$ for the change from baseline to day 10) (fig 3B).

\section{PLATELET AGGREGATION}

A total of 13 patients were analysed for platelet aggregation, although due to missing data, values from 7 to 12 patients are available when changes from baseline are considered. Figure 4 shows that arachidonic acid induced platelet aggregation, which is dependent on COX-1 mediated $\mathrm{TXA}_{2}$ formation, was largely unaffected by nimesulide. In contrast, there was marked suppression of arachidonic acid induced platelet aggregation throughout administration of naproxen (Friedman analysis $\mathrm{p}<0.001$ on days 3,10 , and 15). Treatment

Table 4 Intestinal absorption and permeability before and after nimesulide and naproxen (mean (SEM) and [median]) ( $\mathrm{n}=23$ )

\begin{tabular}{|c|c|c|c|c|c|c|}
\hline \multirow[b]{2}{*}{ Test substance } & \multicolumn{2}{|l|}{ Nimesulide } & \multicolumn{2}{|l|}{ Naproxen } & \multirow{2}{*}{$\begin{array}{l}\text { Nim-Nap } \\
\text { Day } 10\end{array}$} & \multirow[b]{2}{*}{$p$ Value ${ }^{\star}$} \\
\hline & Baseline & Day 10 & Baseline & Day 10 & & \\
\hline 3-o-m-D-glucose (\%) & $46(2.9)[45]$ & $41(2.2)[44]$ & $46(2.2)[47]$ & $41(2.4)[42]$ & $-0.0(2.8)[-1.2]$ & 0.8328 \\
\hline D-xylose $(\%)$ & $28(1.5)[28]$ & $27(1.2)[26]$ & $29(1.3)[30]$ & $27(1.6)[28]$ & $-0.4(2.0)[-2.8]$ & 0.9410 \\
\hline L-rhamnose $(\%)$ & $8.4(0.5)[8.5]$ & $8.0(0.4)[8.0]$ & $9.0(0.7)[9.5]$ & $8.8(0.7)[8.4]$ & $-0.8(0.7)[-0.8]$ & 0.5658 \\
\hline Lactulose/L-rhamnose & $0.028(0.0)[0.023]$ & $0.027(0.0)[0.029]$ & $0.032(0.01)[0.025]$ & $0.042(0.01)[0.034]$ & $-0.015(0.01)^{\star}[-0.007]$ & 0.1070 \\
\hline
\end{tabular}

${ }^{\star}$ Koch test, treatment effect. 

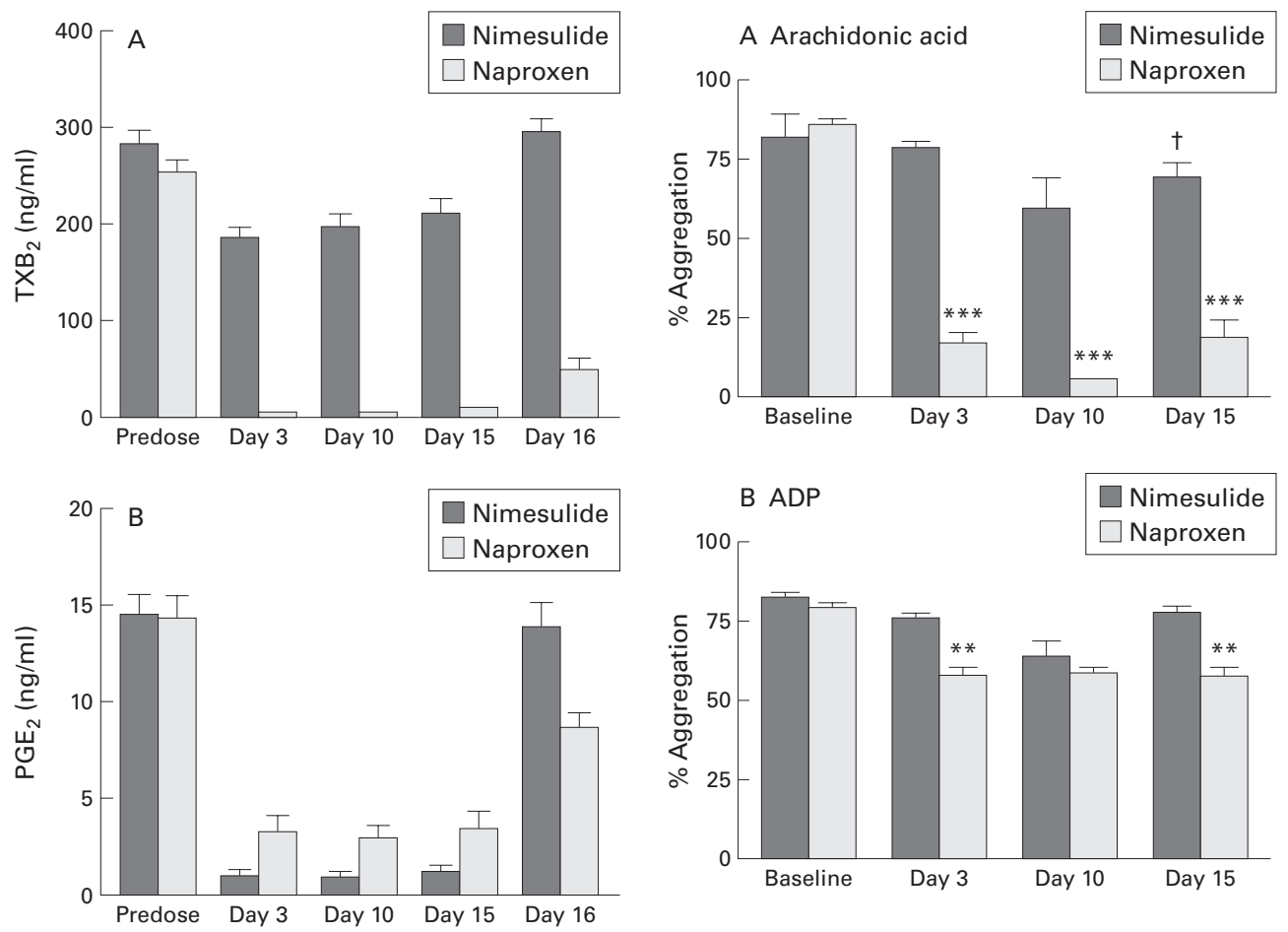

Figure 3 (A) Comparison of the effects of nimesulide and naproxen on serum thromboxane $B_{2}\left(T X B_{2}\right)$ (a measure of $C O X-1$ activity) before and during treatment with nimesulide $100 \mathrm{mg}$ twice daily or naproxen $500 \mathrm{mg}$ twice daily. Data are shown as mean (SEM). Naproxen had a greater effect on serum $T X B_{2}(p<0.001$ for comparison between treatments to day 10). Note that nimesulide reduced serum $\mathrm{Tx} \mathrm{B}_{2}$ on average by $29 \%$ from baseline $(p<0.01)$ and that both drugs markedly reduced plasma $P G E_{2}$. (B) Plasma prostaglandin (PG) $E_{2}$ (a measure of $C O X-2$ activity). Nimesulide had a slightly greater effect on plasma $P G E_{2}(p=0.053$ for comparison between treatments to day 10).

differences (from baseline) were analysed on day 10 and showed a significant $(\mathrm{p}=0.048)$ effect. Platelet aggregation to ADP, where the secondary wave of aggregation is $\mathrm{TXA}_{2}$ dependent, was not significantly altered by nimesulide but was inhibited by naproxen $(\mathrm{p}<0.01$ days 3 and 15). No significant treatment differences were evident on day 10 . Nimesulide had no effect on TRAP induced platelet aggregation, which is independent of $\mathrm{TXA}_{2}$ formation. Similarly, TRAP induced platelet aggregation was largely unaffected by naproxen, although a small degree of inhibition was noted on day 15 . No treatment difference was evident on day 10 .

PLASMA LEVEL OF NIMESULIDE AND NAPROXEN

Following the last dose, plasma concentrations of nimesulide were $5.4(0.4)$ (range 0.13-11.4) $\mu \mathrm{g} / \mathrm{ml}$ at one hour and $5.5(0.3)$ (range 3.1-8.2) $\mu \mathrm{g} / \mathrm{ml}$ at two hours, falling to $4.2(0.3)$ (range 1.2-7.8) at four hours. Corresponding naproxen plasma levels were 70 (4) (range 22-110), 86 (4) (range 20-127), and 6.4 (2) (range 18-91) $\mu \mathrm{g} / \mathrm{ml}$. Plasma concentrations fell to undetectable levels for both drugs within 48 hours of discontinuation.

\section{Discussion}

Gastric and small intestinal damage is common in short and long term users of NSAIDs. NSAID induced gastroduodenal ulceration is

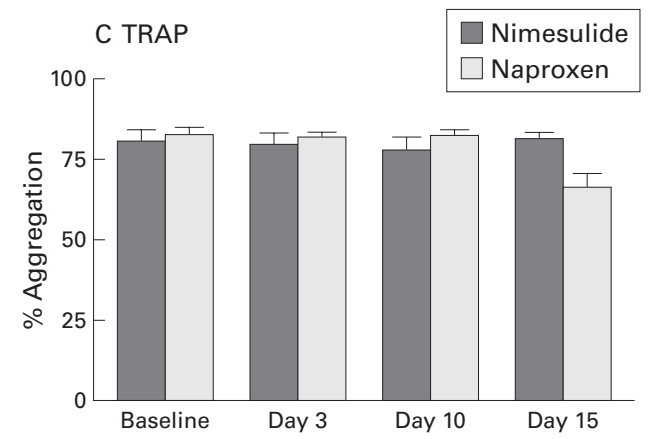

Figure 4 Comparison of the effects of nimesulide and naproxen on platelet aggregation to arachidonic acid $(A)$, adenosine diphosphate $(A D P)(B)$, and thrombin receptor activator peptide (TRAP) (C) before and during treatment with nimesulide $100 \mathrm{mg}$ twice daily or naproxen $500 \mathrm{mg}$ twice daily. Data are shown as mean (SEM). ${ }^{\star *} p<0.01$ $\star \star \star x<0.001$ for changes from baseline; $t p=0.048$ for comparison between treatments.

associated with life threatening bleeding or perforation in an estimated 1 in 5000-20 000 prescriptions. ${ }^{41}$ NSAID induced enteropathy may manifest as iron deficiency anaemia, hypoalbuminaemia due to protein loss, ${ }^{10}$ and rarely as small and large intestinal strictures. ${ }^{42}$ The mechanism of NSAID induced injury is thought to reflect, at least in part, inhibition of cyclooxygenase and loss of cytoprotective prostaglandins, although a direct "topical effect" may also play a role. ${ }^{5}$

Here, we examined the degree of gastroduodenal and small intestinal injury with nimesulide, a relatively selective COX-2 inhibitor during short term administration of the drug. Short term studies are thought to over represent erosive damage by NSAIDs compared with long term studies. However, they are suitable for the purpose of examining the effect of inhibiting COX as they avoid the confounding effect of "adaptation" whereby the damaging effects of COX inhibition is over- 
come in time. The range and prevalence of the gastroduodenal damage by naproxen was in keeping with that previously described. ${ }^{43-45}$ By comparison, gastric damage with nimesulide was significantly less and $71 \%$ of patients remained within Lanza $0-1$. This degree of gastric tolerability was similar to that described with the highly selective COX-2 inhibitors celecoxib $^{46}$ and rofecoxcib. ${ }^{47}$

As reported previously with NSAIDs, ${ }^{44} 45$ duodenal damage was less marked than gastric damage and again was significantly less with nimesulide that naproxen. Nevertheless, a duodenal ulcer was found in a single subject on nimesulide who was positive for $H$ pylori. Parenthetically, $H$ pylori infection had no synergistic effect on damage caused by either drug in this study although this has been reported previously. ${ }^{48}$

Increased permeability of the small intestine has been documented with most conventional NSAIDs. ${ }^{51}$ In this study, nimesulide failed to alter intestinal permeability, in keeping with animal studies. ${ }^{49}$ In contrast, naproxen increased intestinal permeability, as shown previously in humans. ${ }^{50}$ To date, all NSAIDs that increases intestinal permeability are associated with a high prevalence $(40-65 \%)$ of NSAID enteropathy, measured as excretion of calprotectin. ${ }^{51}$ Not surprisingly then, naproxen but not nimesulide increased intestinal inflammation. Although it has been suggested that inflammation may be delayed for six months, ${ }^{52}$ it has been reported earlier, ${ }^{53}$ in keeping with our study.

The improved gastrointestinal tolerability of nimesulide is consistent with its relative COX-2 selectivity and maintenance of gastric prostaglandin formation. As a measure of gastric COX activity, we examined generation of PGs in gastric mucosal biopsies. Nimesulide did not alter formation of either $\mathrm{PGE}_{2}$ or $\mathrm{PGI}_{2}$ in the stomach. $\mathrm{PGE}_{2}$ is the major product of gastric epithelial cells. ${ }^{19}$ However $\mathrm{PGE}_{2}$ is also generated by platelets so that any inhibitory effect of an NSAID could be due to inhibition of platelets contaminating the biopsies. To address this issue, we measured 6-keto $\mathrm{PGF}_{10}$, a metabolite of $\mathrm{PGI}_{2} . \mathrm{PGI}_{2}$ is generated by nucleated cells, such as gastric epithelial and vascular endothelial cells. ${ }^{54}$ Naproxen inhibited both products whereas nimesulide had little effect on gastric $\mathrm{PGE}_{2}$ or 6-keto-PGF $\mathrm{PG}_{1 \alpha}$ at a time when there were substantial levels of the drug in blood.

Studies in whole blood allowed us to compare the relative selectivity of the two compounds for the COX isoforms. Serum $\mathrm{TXB}_{2}$, a measure of COX-1 activity of platelets, ${ }^{21}$ is highly sensitive to inhibition as platelets are incapable of regenerating new enzyme. Nimesulide inhibited serum $\mathrm{TXB}_{2}$ by about $30 \%$ over the period of the study, as has been reported with the highly selective COX-2 inhibitor celecoxcib. ${ }^{55}$ However, it is unlikely that this modest effect would alter haemostatic function, as very marked ( $>95 \%$ ) inhibition of platelet COX-1 is required to suppress platelet aggregation. ${ }^{56}$ Indeed, platelet aggregation to arachidonic acid and ADP, which is $\mathrm{TXA}_{2}$ dependent, was preserved.

As a marker of a COX-2 effect, we used an assay developed by Panaro and colleagues ${ }^{38}$ in which COX-2 in monocytes is induced by LPS, resulting in $\mathrm{PGE}_{2}$ formation. Both drugs suppressed $\mathrm{PGE}_{2}$ formation resulting from LPS treatment. This relative selectivity of nimesulide for COX-2 demonstrated in vivo is consistent with the selectivity seen in vitro at peak plasma levels achieved $(\sim 18 \mu \mathrm{M}$ and $98 \%$ protein bound). ${ }^{27}$

In summary, nimesulide causes less endoscopic and functional evidence of gastrointestinal injury compared with naproxen. This is consistent with our findings showing that nimesulide is a selective COX-2 inhibitor in vivo, with little effect on haemostatic function or gastric prostaglandin formation. A critical issue is whether the short term endoscopic benefits seen with a selective COX-2 inhibitor such as nimesulide translate into a more long term benefit, particularly a reduction in bleeding and perforation. In addition, it remains to be seen if an anti-inflammatory effect will ensue from COX-2 inhibition alone, in that COX-1 has been implicated in some models of inflammation. Indeed, in a mouse model of inflammation, Wallace and colleagues reported a significant reduction in inflammation with nimesulide but only at doses that also inhibited COX $-1 .^{57}$

This study was supported by a grant from Helsinn Healthcare SA.

1 Paulus HE. FDA arthritis advisory committee meeting: postmarketing surveillance of non-steroidal antiinflammatory drugs. Arthritis Rheum 1985;28:1168-9.

2 Langman MJS. Epidemiologic evidence of the association between peptic ulceration and anti-inflammatory drug use. Gastroenterology 1989;96(suppl):640-6.

3 Committee on Safety of Medicines CSM update. Nonsteroidal anti-inflammatory drugs and serious gastrointestinal adverse reactions-I. BMף 1986;292:614-16.

4 Committee on Safety of Medicines: CSM update. Nonsteroidal anti-inflammatory drugs and serious gastrosteroidal anti-inflammatory drugs and serious gast
intestinal adverse reactions-II. BMf 1986;292:1 190.

5 Bjarnason I, Hayllar J, Macpherson AJ, et al. Side effects of non-steroidal antiinflammatory drugs on the small and large intestine. Gastroenterology 1993;104:1832-47. 6Silverstein FE, Graham DY, Senior JR, et al. Misoprostol verstein FE, Graham DY, Senior JR, et al. Misoprostol arthritis receiving NSAID. Ann Intern Med 1995;123:2419.

7 Lockard OO, Ivey KJ, Butt JH, et al. The prevalence of duodenal lesions in patients with rheumatic disease on chronic aspirin therapy. Gastrointest Endosc 1980;26:5-7.

8 Gabriel SE, Jaakkimainen L, Bombardieri C. Risk for serious gastrointestinal complications related to use of NSAID's. A meta-analysis. Ann Intern Med 1991;115:78796.

9 Armstrong CP, Blower AL. Non-steroidal antiinflammatory drugs and life threatening complications of peptic ulceration. Gut 1987;28:527-32.

10 Bjarnason I, Zanelli G, Prowse P, et al Blood and protein loss via small intestinal inflammation induced by non steroidal anti-inflammatory drugs. Lancet 1987;2:711-14.

11 Matsuhashi N, Yamada A, Hiraishi M, et al. Multiple strictures of small intestine after long term NSAID drug herapy. Am $\mathcal{F}$ Gastroenterol 1992;87:1183-6.

12 Merlie JP, Fagan D, Mudd J, et al. Isolation and characterization of the complementary DNA for sheep seminal vesicle prostaglandin endoperoxide synthase cyclooxygenase. $\mathcal{F}$ Biol Chem 1988;263:3550-3.

13 DeWitt DL, Meade EA. Serum and glucocorticoid regulation of gene transcription and expression of the prostaglandin $\mathrm{H}$ synthase-1 and prostaglandin $\mathrm{H}$ synthase-2 isozymes. Arch Biochem Biophys 1993;306:94102.

14 Jones DA, Carlton DP, McIntyre TM, et al. Molecular cloning of human prostaglandin endoperoxide synthase type II and demonstration of expression in response to cytokines. f Biol Chem 1993;268:9049-54.

15 O'Bannon MK, Winn VD, Young DA. cDNA cloning and functional activity of a glucocorticoid-regulated inflamma- 
tory cyclooxygenase. Proc Natl Acad Sci USA 1992;89:

16 Vane JR, Mitchell JA, Appleton I, et al. Inducible isoforms of cyclooxygenase and nitric oxide synthase in inflammation
Proc Natl Acad Sci USA 1994;91:2046-50.

17 Seibert K, Zhang Y, Leahy K, et al. Pharmacological and biochemical demonstration of the role of cyclooxygenase 2 in inflammation and pain. Proc Natl Acad Sci USA 1994;91:12013-17.

18 Kargman S, Charleson S, Cartwright M, et al. Characterization of prostaglandin $\mathrm{G} / \mathrm{H}$ synthase 1 and 2 in rat, dog, monkey, and human gastrointestinal tracts. Gastroenterology 1996:111:445-54

19 Fu S, Ramanujam KS, Wong A, et al. Increased expression and cellular localization of inducible nitric oxide synthase and cyclooxygenase 2 in Helicobacter pylori gastritis. Gastroenterology 1999;116:1319-29.

20 Masferrer JL, Zweifel BS, Manning PT, et al. Selective inhibition of inducible cyclooxygenase 2 in vivo is antiinflammatory and nonulcerogenic. Proc Natl Acad Sci USA 1994;91:3228-32.

21 Patrono C, Ciabbatoni G, Patrignani Ppugliese F, et al. Clinical pharmacology of platelet cyclooxygenase inhibition. Circulation 1985;72:117-18.

22 Langenbach R, Morham SG, Tiano HF, et al. Prostaglandin synthase 1 gene disruption in mice reduces arachidonic acid induced inflammation and indomethacin-induced gastric ulceration. Cell 1995;83:483-92.

23 Laneuville O, Breuer DK, Dewitt DL, et al. Differential inhibition of human prostaglandin endoperoxide $\mathrm{H}$ synthases- 1 and -2 by nonsteroidal anti-inflammatory drugs. F Pharmacol Exp Ther 1994;271:927-34.

24 Chan CC, Boyce S, Brideau C, et al. Pharmacology of a selective cyclooxygenase-2 inhibitor, L-745,337: a novel nonsteroidal anti-inflammatory agent with an ulcerogenic sparing effect in rat and nonhuman primate stomach. $\mathcal{F}$ Pharmacol Exp Ther 1995;274:1531-7.

25 Khanna IK, Weier RM, Collins PW, et al. 1,2-diarylpyrroles as potent and selective inhibitors of cyclooxygenase- 2 . $\mathcal{F}$ 7:40:1619-33.

26 Cullen L, Kelly K, O'Connor S, et al. Selective inhibition of COX-2 by nimesulide in man. F Pharmacol Exp Ther 1998; 287:578-82.

27 Taniguchi Y, Ikesue A, Yokoyama $\mathrm{K}$, et al. Selective inhibition by nimesulide, a novel non-steroidal antiinflammatory drug, of prostaglandin endoperoxide synthase-2 activity in vitro. Pharm Sci 1995;1:173-5.

28 Lanza FL. Endoscopic studies of gastric and duodenal injury after the use of ibuprofen, aspirin and other NSAIDs. Am f Med 1984;7:19-24.

29 Aabakken L, Larsen S, Osnes M. Visual analogue scale for endoscopic evaluation of NSAID-induced mucosal damage in the stomach and the duodenum. Scand $f$ Gastroenterol 1990;25:443-8.

30 Dixon FM, Genta RM, Yardley JH, et al. Classification and grading of gastritis. Am $\mathcal{F}$ Surg Pathol 1996;20:1161-81.

31 Bjarnason I, Macpherson A, Hollander D. Intestinal permeability: an overview. Gastroenterology 1995;108:156681.

32 Teahon K, Smethurst P, Levi AJ, et al. Intestinal permeability in patients with Crohn's disease and their first degree relatives. Gut 1992;33:320-3.

33 Lim SG, Menzies IS, Lee CA, et al. Intestinal permeability and function in patients infected with human immunodeficiency virus. Scand $\mathcal{F}$ Gastroenterol 1993;28:573-80.

34 Menzies IS, Mount JN, Wheeler MJ. Quantitative estimation of clinically important monosaccharides in plasma by rapid thin layer chromatography. Ann Clin Biochem 1978;15:65-76.

35 Menzies IS. Transmucosal passage of inert molecules in health and disease. In: Skadhauge E, eds. Intestinal absorption and secretion. Lancaster: MTP press, Falk symposium, 1984:527-43.

36 Dale I, Brandtzaeg P, Fagerholm MK, et al. Distribution of a new myelomonocytic antigen (L-1) in human peripheral blood leucocytes. Am 7 Clin Pathol 1985:84:24-34.

37 Roseth AG, Farerhol MK, Aadland E, et al. Assessment of neutrophil dominating calprotectin in faeces. A methodological study. Scand 7 Gastroenterol 1992;27:793-8.

38 Panaro MR, Greco A, Santini G, et al. Effects of the novel anti-inflammatory compounds, N-[2-(cyclohexyloxy)-4- nitrophenyl] methanesulphonamide (NS398) and 5-methanesulphonamido-6-(2,4-difluorthio-phenyl)-1indanone $(\mathrm{L}-745,337)$, on the cyclo-oxygenase of human blood prostaglandin endoperoxide synthases. Br f Pharmacol 1995;116:2429-34.

39 Koch GG. The use of non-parametric methods in the statistical analysis of the two-period change-over design. Biometrics 1972;28:577-85

40 Bode C, Maute G, Bode JC. Prostaglandin E2 and prostaglandin $\mathrm{F} 2$ alpha biosynthesis in human gastric mucosa: effect of chronic alcohol misuse. Gut 1996;39: $348-52$.

41 MacDonald TM, Morant SV, Robinson GC, et al. Association of upper gastro-intestinal toxicity of NSAIDs with continued exposure: Cohort study. BMF 1997;315: 1333-7.

42 Bjarnason I, Price AB, Zanelli G, et al. A clinicopathological feature of NSAID induced small intestinal strictures. Gastroenterology 1988;94:1070-4.

43 Bjarnason I, MacPherson A, Rotman $\mathrm{H}$, et al. A randomized, double-blind, cross-over, competitive endoscopy study on the gastrointestinal tolerability of a highly specific COX-2 inhibitor flosulide and naproxen. Scand $\mathcal{F}$ Gastroenterol 1997;32:126-30.

44 Lanza FL, Rack MF, Lynn M, et al. An endoscopic comparision of the effect of etodolac, indomethacin, ibuprofen, naproxen and placebo on the gastro-intestinal mucosa. F Rheumatol 1987;14:338-41.

45 Bardhan KD, Bjarnason I, Scott DL, et al. The prevention and healing of acute NSAID-associated gastroduodenal mucosal damage by misoprostol. Br f R Reumatol 1993;32: $990-5$.

46 Simon LS, Weaver AL, Graham DY, et al Anti-inflammatory and upper gastrointestinal effects of celecoxib in rheumatoid arthritis: a randomized controlled trial. $\mathcal{F} A M A$ 1999;282:1921-8.

47 Hawkey C, Laine L, Simon T, et al. Comparison of the effect of rofecoxib (a cyclooxygenase 2 inhibitor), ibuprofen, and placebo on the gastroduodenal mucosa of patients with osteoarthritis: a randomized, double-blind, placebocontrolled trial. The Rofecoxib Osteoarthritis Endoscopy Multinational Study Group. Arthritis Rheum 2000;43:370-

48 Cullen DJE, Hawkey GM, Greenwood DC, et al. Peptic ulcer bleeding in the elderly: Relative roles of Helicobacter pylori and NSAIDs. Gut 1997;41:459-62.

49 Sigthorsson G, Jacob M, Wrigglesworth JM, et al. A comparison of indomethacin and nimesulide, a selective COX-2 inhibitor, on key patho-physiological steps in the pathogenesis of NSAID enteropathy in the rat. Scand 7 Gastroenterol 1998;38:728-35.

50 Aabakken L, Osnes M. $51^{\mathrm{Cr}}$ ethylenediaminetetraacetic acid absorption test. Effect of naproxen, a non-steroidal anti-inflammatory drug. Scand $\mathcal{7}$ Gastroenterol 1990;25: 917-24.

51 Sigthorsson G, Tibble J, Hayllar J, et al. Intestinal permeability and inflammation in patients on NSAIDs. Gut 1998;43:506-11.

52 Bjarnason I, Zanelli G, Smith T, et al. NSAID-induced intestinal inflammation in humans. Gastroenterology 1987; 93:480-9.

53 Meiling TR, Aabakken L, Roseth A, et al. Faecal calprotectin shedding after short term treatment with NSAIDs. Scand 7 Gastroenterol 1996;31:339-44.

54 Fitzgerald GA, Brash AR, Falardeau P, et al. Estimated rate of prostacyclin secretion into the circulation of normal man. $\mathcal{F}$ Clin Invest 1981;68:1272-6.

55 McAdam BF, Catella-Lawson F, Mardini IA, et al. Systemic biosynthesis of prostacyclin by cyclooxygenase (COX)-2: the human pharmacology of a selective inhibitor of COX-2. Proc Natl Acad Sci USA 1999;96:272-7.

56 Svensson J, Samuelssom K. Inhibition of platelet function by low dose acetylsalicylic acid in patients with cerebrovascular disease. Thromb Res 1983;31:499-503.

57 Wallace JL, Bak A, McKnight W, et al. Cyclooxygenase 1 contributes to inflammatory responses in rats and mice: mplications for gastrointestinal toxicity. Gastroenterology 998;115:101-9. 